\title{
An Econometric Analysis of Inflation and Unemployment in Lebanon: A Vector Error Correction Model (VECM)
}

\author{
Mohammad Khanssa ${ }^{1}$, Wafaa Nasser ${ }^{2}$ \& Abbas Mourad ${ }^{1,2,3}$ \\ ${ }^{1}$ Faculty of Sciences, Branch 1- Lebanese University, Hadath, Lebanon \\ ${ }^{2}$ Faculty of Economics and Business Administration, Lebanese University, Hadath, Lebanon \\ 3 Mathematics and Applications Laboratory, Research Unit «Mathématiques et modélisation», Faculty of \\ Sciences, Saint-Joseph University, Mansourieh, Lebanon \\ Correspondence: Wafaa Nasser, Faculty of Economics and Business Administration, Lebanese University, \\ Hadath, Lebanon. E-mail: wafaa.nasser1@ul.edu.lb
}

Received: December 5, 2017

Accepted: January 9, 2018

Online Published: January 20, 2018

doi:10.5539/ijef.v10n2p133

URL: https://doi.org/10.5539/ijef.v10n2p133

\begin{abstract}
This paper uses econometric modeling to test the nature of the relationship between unemployment and inflation in Lebanon throughout the period 1993-2014. It takes the Phillips curve relationship as a reference for the tests. Cointegration, Granger causality and VECM were used to test the relationship both in the short and in the long run. The study resulted in finding out that the Phillips curve relationship doesn't hold in Lebanon in the short run and came to a conclusion that there is a one-way causality relationship in the long run from unemployment to inflation and not in the opposite direction.
\end{abstract}

Keywords: unemployment, inflation, cointegration, Vector Error Correction Model (VECM), Granger causality

\section{Introduction}

The trade-off between unemployment and inflation was first noted in 1958 by William Phillips who brought forward what is known today as the Phillips curve (Phillips, 1958). The Phillips curve is a fitted negatively sloped curve that was initiated through studying the relationship between unemployment and wage inflation in the United Kingdom. Further research showed with time that the Phillips theory was not very accurate and it had many shortcomings, hence modifications were made to it, which brought to light new theories such as the expectations augmented Phillips curve theory, the "natural rate" of unemployment concept and the NAIRU (nonaccelerating inflation rate of unemployment).

Ever since the trade-off between unemployment and inflation was introduced by Phillips, many empirical studies were performed to test the real essence of the relationship between these two variables. The relationship between unemployment and inflation is of particular importance due to its relevancy to policy makers especially with regards to monetary policies that target low inflation rates. In cases where the Phillips relationship holds, implementing policies that intend at reducing inflation could become a tricky job since they possibly will result in an augmentation of the level of unemployment.

This paper aims at testing the existence of a trade-off between unemployment and inflation at the level of the Lebanese economy. Having a study that explains the relationship between these variables in Lebanon is of particular significance given that both inflation and unemployment have been fluctuating hard and reaching high levels throughout the past few decades. 


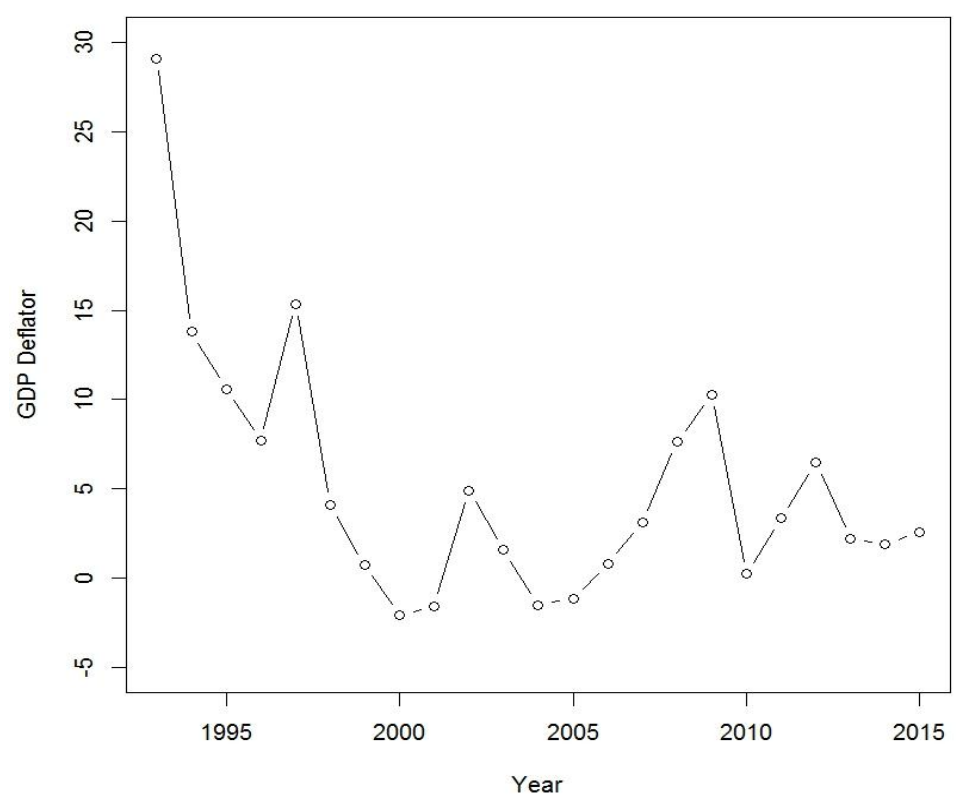

Figure 1. Inflation in Lebanon 1993-2014 (measured by GDP deflator)

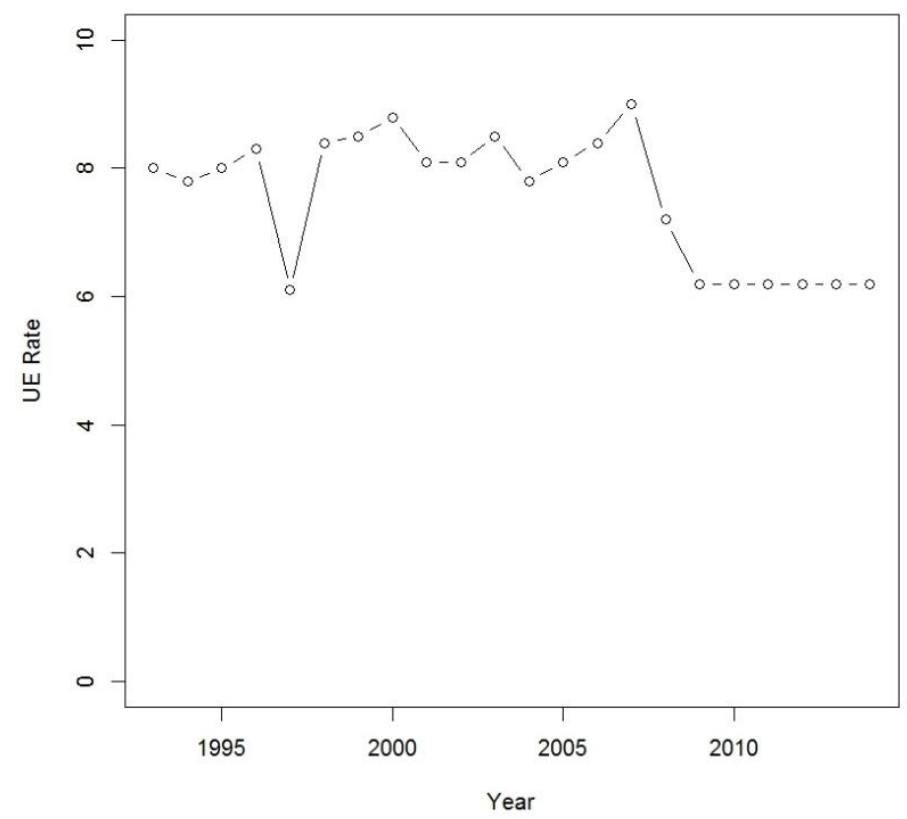

Figure 2. Unemployment rate in Lebanon 1993-2014 (as a percentage)

The paper first introduces the theoretical background of the Phillips curve relationship and its proceeding theories then checks through previous studies whether there exists a variation in the applicability of those theories between developed and developing countries of the world. To analyze data on inflation and unemployment in Lebanon, the study uses the vector auto regression (VAR) and the vector error correction model (VECM). The presence of a co-integration relationship between two variables leads to the existence of a causal relationship between them in at least one direction. This causal relationship can be analyzed using the Granger causality test, which relies on the vector auto regression (VAR) and the vector error correction model (VECM).

\section{Literature Review}

According to Wallich (1979), there exist three causes for which inflation seems to increase rather than decrease unemployment. These causes are the policies used to curb inflation, the acceleration towards hyper inflation and finally the disincentives to investment. Tandon (1978) analyzed the case of Canada to find that there is a conflict 
between the objectives of price stability and those of low unemployment. In an empirical study done by Favero (1988), an econometric analysis of UK data about inflation and unemployment found that a NAIRU model is a better policy analysis tool than the Phillips curve. More recently (Nwala, 2003), came out with the result that in the U.S. there is a momentary trade-off in the adaptive expectations model between unemployment and inflation, however in the long run this trade-off is eliminated through wage and price adjustments. This was confirmed by Ribba (2006), who added that aggregate demand shocks and monetary policy shocks both push unemployment and inflation in opposite directions in the short run, however in the long run permanent supply shocks shape an upward sloping Phillips curve.

Other authors took a different dimension of this analysis through studying the relationship between unemployment and inflation throughout their relationship with wages. Duanev (2005) reached a conclusion while examining the Ukrainian economy that the functions of unemployment and inflation are independent variables and it is impossible to affect unemployment though inflation.

While studying the Phillips curve relationship, multiple empirical methodologies were used and multiple statistical tools were applied to analyze the relationship between unemployment and inflation in depth. When testing the NAIRU framework in Germany; Schreiber and Wolters (2007) applied a VAR cointegration analysis to find a negative long run Phillips curve relationship. Furuoka (2007), also used the VAR cointegration analysis to find that there exists a long run Phillips curve relationship in the economy of Malaysia. They also found a causal relationship between the two studied variables. Multiple other studies also used the VAR cointegration model to test this relationship in different developed as well as developing countries (Chiarini \& Piselli, 1997; Fanelli, 2008; Juselius, 1998). In our study, we will also apply the VAR and VECM models to analyze this relationship in the case of Lebanon, these two models are well fitting for forecasting in time series analysis. We will also use the granger causality technique in order to test relationship between variables and the direction of causation.

\section{Methodology}

This study's identified model is a two variables model, which hypothesizes inflation rate as a function of unemployment rate.

$$
I N F_{t}=F\left(U N E_{t}\right)
$$

Where, INF represents annual inflation rate in Lebanon, UNE represents annual unemployment rate. The sample includes 22 annual data from 1993 till 2014 and was obtained from the World Bank's database.

Stationarity Test: Stationarity of a series is an important phenomenon because it can influence its behavior. If $\mathrm{X}$ and $\mathrm{Y}$ are two non-stationary series and we regress $\mathrm{X}$ on $\mathrm{Y}$ in equation (2), we will obtain spurious regression or nonsense regression (Yule, 1926).

$$
Y_{t}=\beta_{0}+\beta_{1} X_{t}+\varepsilon_{t}
$$

If the series has a unit root, this means that the series is non-stationary. If the series does not contain a unit root, the series is stationary. The stationarity test tests the null hypothesis of whether a unit root is present in an autoregressive model. Unit root test is useful to determine the order of integration of the variables. Augmented Dickey-Fuller test (ADF) and Phillips-Perron test (PP) have been used to test the stationarity of the given series.

Order of integration: If a series is stationary, then it is integrated of order $0 ; I(0)$. If a series is not stationary and it is integrated of order 1 (i.e., it is $I(1)$ ), its first differences are $I(0)$, that is, stationary. Similarly, if a time series is $I(2)$, its second difference is $I(0)$. In general, if a time series is $I(d)$, after differencing it $d$ times we obtain an $I(0)$ series.

Where $\Delta$, known as the first difference operator, tells us to take successive differences of the variables in question. Thus, $\Delta Y_{t}=Y_{t}-Y_{t-1}$ and $\Delta X_{t}=X_{t}-X_{t-1}$.

Johansen and Juselius Co-integration Test: Johansen-Juselius technique is adopted to test for the existence of co-integration relationship between the non-stationary series of the two variables.

The Johansen-Juselius procedure of co-integration enables us to examine the existence of co-integration between two non-stationary series which requires that the rank of the matrix $\pi$ does not have a full $\operatorname{rank}(0<\operatorname{rank}(\pi)=\mathrm{r}<$ $\mathrm{n})$. Where (r) is the number of co-integration vectors, (n) is the number of variables and $\pi$ can be written in terms of the vector or matrix of adjustment parameters $\alpha$ and the vector or matrix of co-integrating vectors $\beta^{\prime}$ as $\pi=$ $\alpha \beta^{\prime}$. This procedure depends on the Trace test $\left(\lambda_{\text {trace }}\right)$ and The Maximum Eigenvalues test $\left(\lambda_{\max }\right)$ to determine the number of Co-integration vectors between variables based on a likelihood ratio test (LR).

The trace test $\left(\lambda_{\text {trace }}\right)$ is defined as: $\lambda_{\text {trace }}(r)=-T \times \sum_{i=r+1}^{n} \log \left(1-\hat{\lambda}_{i}\right)$ 
The null hypothesis is that the number of co-integration vectors is $\leq \mathrm{r}$ against the alternative hypothesis that the number of co-integration vectors $=r$.

The Maximum Eigenvalues test $\left(\lambda_{\max }\right)$ is defined as: $\lambda_{\max }(r, r+1)=-T \times \log \left(1-\hat{\lambda}_{r+1}\right)$

The null hypothesis that the number of co integration vectors $=r$ against the alternative that they are $r+1$.

Granger-causality: The results of stationarity and co-integration tests will determine how Granger-causality test should be applied, as follows:

If the series (UNE) and (INF) are stationary, the standard Granger-causality test should be carried out by estimating the following Vector Auto Regression (VAR):

$$
\begin{gathered}
\mathrm{UNE}_{t}=\alpha+\sum_{i=1}^{m} \beta_{1 i} \mathrm{UNE}_{t-i}+\sum_{i=1}^{m} \beta_{2 i} I N F_{t-i}+\varepsilon \\
I N F_{t}=\alpha+\sum_{i=1}^{m} \beta_{3 i} I N F_{t-i}+\sum_{i=1}^{m} \beta_{4 i} \mathrm{UNE}_{t-i}+\varepsilon
\end{gathered}
$$

In models (3) and (4), the subscripts denote time periods and $\varepsilon$ is a white noise error. The constant parameter $\alpha$ represents the constant growth rate of $\mathrm{UNE}_{t}$ in equation (3) and $I N F_{t}$ in equation (4). We can obtain two tests from this analysis: the first examines the null hypothesis that the $I N F_{t}$ does not Granger-cause $\mathrm{UNE}_{t}$ and the second test examines the null hypothesis that the $\mathrm{UNE}_{t}$ does not Granger-cause $I N F_{t}$. If we fail to reject the former null hypothesis and reject the latter, then we conclude that $I N F_{t}$ changes are Granger-caused by a change in $\mathrm{UNE}_{t}$ (Gul \& Ekinc, 2006). Unidirectional causality will occur between two variables if either null hypothesis of equation (3) or (4) is rejected. Bidirectional causality exists if both null hypotheses are rejected and no causality exists if neither null hypothesis of equation (3) nor (4) is rejected (Duasa, 2007).

If the variables (UNE) and (INF) are non-stationary and integrated of order 1, but they are not co-integrated, the Granger-causality test should be carried out by estimating the following Vector Auto-Regression with differentiation (VAR) using the first difference series of both variables:

$$
\begin{aligned}
\Delta \mathrm{UNE}_{t} & =\alpha+\sum_{i=1}^{m} \beta_{1 i} \Delta \mathrm{UNE}_{t-i}+\sum_{i=1}^{m} \beta_{2 i} \Delta I N F_{t-i}+\varepsilon \\
\Delta I N F_{t} & =\alpha+\sum_{i=1}^{m} \beta_{3 i} \Delta \mathrm{INF}_{t-i}+\sum_{i=1}^{m} \beta_{4 i} \Delta U N E_{t-i}+\varepsilon
\end{aligned}
$$

In model (5), (UNE) is caused by past values of both (UNE) and (INF). In model (6), (INF) is caused by past values of the two variables. According to Granger, (INF) causes (UNE) in model (5) if one of the $\left(\beta_{2 i}\right)$ is significantly different from zero, and that (UNE) causes (INF) in model (6) if one of the $\left(\beta_{4 i}\right)$ is significantly different from zero.

Vector Error Correction Model (VECM): If the variables (UNE) and (INF) are non-stationary, integrated of the same order (d), and co-integrated, the Granger-causality test should be carried out through estimating Vector Error Correction Model (VECM), which could have the following form:

$$
\begin{aligned}
\Delta \mathrm{UNE}_{t} & =\alpha_{1}+\sum_{i=1}^{m} \beta_{1 i} \Delta \mathrm{UNE}_{t-i}+\sum_{i=1}^{m} \beta_{2 i} \Delta I N F_{t-i}+\beta_{3} \mu_{t-1}+\varepsilon_{1 i} \\
\Delta I N F_{t} & =\alpha_{2}+\sum_{i=1}^{m} \beta_{4 i} \Delta I N F_{t-i}+\sum_{i=1}^{m} \beta_{5 i} \Delta \mathrm{UNE}_{t-i}+\beta_{6} \eta_{t-1}+\varepsilon_{2 i}
\end{aligned}
$$

Where $\left(\mu_{t-1}\right)$ and $\left(\mathrm{y}_{t-1}\right)$ are error correction terms. The term $\left(\mu_{t-1}\right)$ in (7) is the lagged value of the residuals from the ordinary least squares regression of $\mathrm{UNE}_{t}$ on $\mathrm{INF}_{t}$ and the term $\left(\mathrm{y}_{t-1}\right)$ in (8) corresponds to the lagged value of the residuals from the ordinary least squares regression of $I N F_{t}$ on $U N E_{t}$. It is obvious that (7) and (8) compose a bivariate VAR in first differences augmented by the error-correction terms $\left(\mu_{t-1}\right)$ and $\left(\mathrm{y}_{t-1}\right)$, indicating that VECM model and co-integration are equivalent representations.

According to Engle and Granger (1987), a co-integrated system of two series can be expressed by an error correction model (ECM). ECM is therefore a useful theoretical approach for estimating short and long-term effects of 2 series; in this model causality must run in at least one-way. Within the VECM equation $(7),\left(I N F_{t}\right)$ does not Granger cause $\left(U N E_{t}\right)$ if all $\beta_{2 i}=0$ and $\beta_{3}=0$. Equivalently, in equation (8) $\left(U N E_{t}\right)$ does not Granger cause $\left(I N F_{t}\right)$ if all $B_{5 i}=0$ and $\beta_{6}=0$. Also, $\left(\beta_{3}, \beta_{6}\right)$ the parameters of the error correction term indicate the speed of adjustment of any short-run disequilibrium towards a long-run equilibrium between both variables.

The Granger-causality could be claimed if the parameters $\left(\beta_{2 i}\right.$ and $\left.\beta_{3}\right)$ in (7) and, or $\left(\beta_{5 i}\right.$ and $\left.\beta_{6}\right)$ in (8) are jointly not all equal to zero which can be tested by a simple F-test. Similarly, long-run causality could be claimed if $\left(\beta_{3}\right)$ or $\left(\beta_{6}\right)$, the parameters of the error correction term in (7) or (8) are statistically significant which can be tested by t-test.

The Augmented Dickey-Fuller (ADF), Phillips-Perron (PP), Co-integration tests and the Vector Error Correction Model (VECM) are sensitive to the number of lags. So, the choice of the number of lags actually employed was assigned to Akaike Information Criterion(AIC) and Schwarz Information Criterion (SIC). 


\section{Results and Findings}

As mentioned previously, the variables that we are testing in our model represent the inflation level and the level of unemployment in Lebanon. Inflation was measured through the CPI for the period between 1993 till 2014 and Unemployment was measured as well for the period 1993-2014. Applying the tests that were previously discussed in the methodology section, we start by testing the stationarity of the variables in question.

\subsection{Stationarity Test}

Table 1.ADF and PP unit root tests

\begin{tabular}{cccccc}
\hline & Series & \multicolumn{2}{c}{ With intercept } & \multicolumn{2}{c}{ With intercept and trend } \\
\cline { 3 - 5 } & Levels & ADF & PP & ADF & PP \\
\hline \multirow{2}{*}{ UNE } & test statistic values & -1.927 & -1.927 & -2.660 & -2.660 \\
& critical value & -2.998 & -2.998 & -3.662 & -3.662 \\
\multirow{2}{*}{ INF } & test statistic values & -2.821 & -2.808 & -2.885 & -2.642 \\
& critical value & -2.998 & -2.998 & -3.662 & -3.622 \\
\hline
\end{tabular}

Table 1 Results of the ADF and PP tests show that the given variables are not stationary at a 5\% level of significance (test statistic values are less than the critical value)

\subsection{Order of Integration}

Table 2 shows that the null hypotheses for all the time series are rejected at their first differences (ADF and PP test statistic values are greater than the critical value at $5 \%$ level of significance). The two variables became stationary and do not contain a unit root in first difference. So the two variables are integrated of order 1, I(1).

Table 2. ADF and PP tests for differencing series

\begin{tabular}{llllll}
\hline & Series & \multicolumn{2}{c}{ With intercept } & \multicolumn{2}{c}{ With intercept and trend } \\
\cline { 3 - 5 } & Levels & ADF & PP & ADF & PP \\
\hline \multirow{2}{*}{$\Delta \mathrm{UNE}$} & test statistic values & -5.988 & -6.778 & -5.810 & -7.391 \\
& critical value & -3.004 & -3.004 & -3.710 & -3.632 \\
\multirow{2}{*}{$\Delta \mathrm{INF}$} & test statistic values & -7.955 & -7.076 & -9.430 & -8.359 \\
& critical value & -3.004 & -3.004 & -3.632 & -3.632 \\
\hline
\end{tabular}

\subsection{Determination of Lags}

As proposed by Stock and Watson (Stock \& Watson, 1993), the VECM is sensitive to the number of lag order. We chose the model with minimal AIC and SC values (Bozdogan, 1987).

Table 3. Lag-order selection criterion

\begin{tabular}{cccc}
\hline Lag & Log L & AIC & SC \\
\hline 0 & -81.96224 & 8.838131 & 8.937546 \\
1 & -71.77079 & $8.186399^{*}$ & $8.484643^{*}$ \\
2 & -71.25205 & 8.552847 & 9.049920 \\
3 & -69.15973 & 8.753655 & 9.449558 \\
4 & -68.38906 & 9.093585 & 9.988317 \\
5 & -61.86449 & 8.827841 & 9.921402 \\
\hline
\end{tabular}

* Indicate the order of lag selected by AIC and SC.

The result in Table 3 shows a lag order of one. Therefore, we proceed to further tests with a lag order 1.

\subsection{Co-Integration Test}

To test if the two variables are co-integrated and to know the number of co-integration vectors we start by testing $\mathrm{H}_{0}: \mathrm{r}=0$. If it is rejected, we test $\mathrm{H}_{0}: \mathrm{r}=1$. When a test is not rejected, we stop testing there and the final value of $r$ is the number of co-integrating relations (vector). The results of co-integration are present in the Table 4. 
Table 4. Johansen-Juselius co-integration trace and maximum eigenvalue test

\begin{tabular}{ccccc}
\hline Unrestricted Co-integration Rank Test (Trace) & \multicolumn{5}{c}{0.05} \\
\hline Hypothesized & Eigenvalue & Statistic & Critical Value & Prob. \\
No. of CE(s) & 0.965191 & 75.99368 & 15.49471 & 0.0000 \\
None $(\mathrm{r}=0)$ & 0.091876 & 2.120239 & 3.841466 & 0.1454 \\
\hline At most $1(\mathrm{r} \leq 1)$ & & & \\
\hline Unrestricted Co-integration Rank Test (Maximum Eigenvalue) & 0.965191 & 73.87344 & 14.26460 & 0.0000 \\
None $(\mathrm{r}=0)$ & 0.091876 & 2.120239 & 3.841466 & 0.1454 \\
At most $1(\mathrm{r} \leq 1)$ & & & & \\
\hline
\end{tabular}

In this test, the null hypothesis of no Co-integration $(r=0)$ based on both the trace test and the maximum Eigen-values test between UNE and INF is rejected at 5\% level of significance (75.99368>14.26460 and $73.87344>14.26460)$. The null hypothesis that $(\mathrm{r} \leq 1)$ is not rejected $(2.120239<3.841466)$. We can thus conclude that the final number of co-integrated vectors is equal to one, i.e. rank $(\pi)=1$. Therefore, the series are co-integrated.

Table 5 shows the parameters of co-integration equation of INF on UNE calculated by the Johansen-Juselius procedure.

Table 5. Normalized co-integrating coefficients (standard error in parentheses)

\begin{tabular}{cc}
\hline $\mathrm{INF}$ & $\mathrm{UNE}$ \\
\hline 1.000 & 0.14 \\
& $(1.158)$ \\
\hline
\end{tabular}

The normalized relationship is:

$$
I N F_{t}==-0.14 U N E_{t}+11.688
$$

In other words, the unemployment rate is related to decreasing inflation rate. The unemployment rate is likely to decrease inflation rate by $14 \%$. We will proceed to estimate the VECM model.

\subsection{Vector Error Correction Model}

The presence of co-integration between variables suggests a long-term relationship among the variables. In this case, the Vector error correction model (VECM) can be applied. Therefore, we begin by estimating the coefficients of the VECM. Where the VECM is constructed by two equations taking into consideration that the result of lag selection criteria is one, we have:

$$
\begin{gathered}
\Delta U N E_{t}=\alpha_{1}+\beta_{1} \Delta U N E_{t-1}+\beta_{2} \Delta I N F_{t-1}+\beta_{3} \mu_{t-1}+\varepsilon_{1 i} \\
\Delta \mathrm{INF}_{\mathrm{t}}=\alpha_{2}+\beta_{4} \Delta \mathrm{INF}_{\mathrm{t}-1}+\beta_{5} \Delta U N E_{\mathrm{t}-1}+\beta_{6} \mathrm{\eta}_{\mathrm{t}-1}+\varepsilon_{2 \mathrm{i}}
\end{gathered}
$$

The relationship in (10) is tested first and then we test the relationship in equation (11).

Table 6. VECM of equation 10

\begin{tabular}{lllll}
\hline & Coefficient & Std. Error & t-Statistic & p-value \\
\hline$\beta_{1}$ & -0.290563 & 0.226452 & -1.283111 & 0.2157 \\
$\beta_{2}$ & -0.000464 & 0.008439 & -0.055035 & 0.9567 \\
$\beta_{3}$ & -0.000261 & 0.001208 & -0.216381 & 0.8311 \\
$\alpha_{1}$ & -0.121017 & 0.190069 & -0.636700 & 0.5323 \\
\hline
\end{tabular}

Table 6 shows that, the p-value of coefficient $\beta_{3}$ of the error correction term $\mu_{t-1}$ is equal to 0.8311 which is greater than 0.05 , thus the null hypotheses $\left(H_{0}\right): \beta_{3}=0$ cannot be rejected. Thus, $\mathrm{INF}_{\mathrm{t}}$ does not cause $\mathrm{UNE}_{\mathrm{t}}$ in the long term. Now, we need to test the coefficient $\beta_{2}$ of $\Delta I N F_{t-1}$ if it is significant or not. For that reason, we apply Wald test (Table 7). 
Table 7.Wald test of $\beta_{2}$

\begin{tabular}{cccc}
\hline Test Statistic & Value & df & Probability \\
\hline t Statistic & -0.055035 & 18 & 0.9567 \\
F Statistic & 0.003029 & $(1,18)$ & 0.9567 \\
chi-square & 0.003029 & 1 & 0.9561 \\
\hline
\end{tabular}

The p-value of Chi-Square test is equal 0.9561 greater than 0.05 , meaning that the null hypotheses $\left(\mathrm{H}_{0}: \beta_{2}=0\right)$ cannot be rejected, therefore $\mathrm{INF}_{\mathrm{t}}$ does not cause $\mathrm{UNE}_{\mathrm{t}}$ in the short term. This leads us to conclude that inflation does not have any causality on unemployment neither in the short term nor in the long term.

Table 8. VECM of equation 11

\begin{tabular}{ccccc}
\hline Coefficient & Value & Std. Error & t-Statistic & p-value \\
\hline$\beta_{4}$ & -0.050833 & 0.041844 & -1.214811 & 0.2401 \\
$\beta_{5}$ & -0.480329 & 1.122794 & -0.427798 & 0.6739 \\
$\beta_{6}$ & -0.741201 & 0.041688 & -17.77975 & 0.0000 \\
$\alpha_{2}$ & -5.567774 & 0.942398 & -5.908092 & 0.0000 \\
\hline
\end{tabular}

Table 8 shows that, the $\mathrm{p}$-value coefficient $\beta_{6}$ of the error correction term $\eta_{\mathrm{t}-1}$ is less than 0.05 , so the null hypotheses $\left(H_{0}\right): \beta_{6}=0$ is rejected. Thus, $\mathrm{UNE}_{\mathrm{t}}$ causes Inflation $\mathrm{INF}_{\mathrm{t}}$ in the long term. Now, to test the coefficient $\beta_{5}$ of lagged value $\Delta U N E_{t-1}$ if it significant or not, we should apply Wald test.

Table 9. Wald test of $\beta_{5}$

\begin{tabular}{cccc}
\hline Test Statistic & Value & df & Probability \\
\hline Test Statistic & -0.427798 & 18 & 0.6739 \\
t Statistic & 0.183011 & $(1,18)$ & 0.6739 \\
F Statistic & 0.183011 & 1 & 0.6688 \\
\hline
\end{tabular}

The p-value of chi-square test is equal 0.6688 which is more then 0.05 , the null hypotheses $\left(H_{0}\right): \beta_{5}=0$ cannot thus be rejected, therefore UNE does not cause INF in the short run.

The long run relationship between inflation and unemployment for one co-integrating vector for Lebanon throughout the period 1993-2014 is displayed below.

Generally, the result of the INF (equation 9) as shown above is found to be satisfactory in terms of correct signs. It is seen that unemployment rate has correct negative sign with the inflation rate relationship.

\subsection{Granger Causality Test}

Estimation results for granger causality between the variables are presented in Table 10. The study by Gul and Ekinc (2006), used chi-square statistics and probability to measure causality between the variables.

Table 10. Granger causality test

\begin{tabular}{cccc}
\hline Null Hypothesis & $\chi^{2}$ & Probability & Decision \\
\hline$\Delta$ UNE does not Granger-cause $\triangle \mathrm{INF}$ & 0.385547 & 0.8247 & DO NOT REJECT \\
$\Delta$ INF does not Granger-cause $\Delta \mathrm{UNE}$ & 0.979076 & 0.6129 & DO NOT REJECT \\
\hline
\end{tabular}

Chi-Square statistics and probability values constructed under the null hypothesis of non-causality show that there is no causal relationship between those variables. Non-Significant probability values denote non-rejection of the null hypothesis. This study cannot reject the null hypothesis if the probability value is more than $5 \%$ otherwise do not reject the null hypothesis if the probability value is less than $5 \%$. It is found that $\Delta \mathrm{INF}$ does not "Granger cause" $\triangle \mathrm{UNE}$ unidirectional or $\triangle \mathrm{UNEdoes}$ not "Granger cause" $\triangle \mathrm{INF}$ unidirectional at the $5 \%$ significance level.

\section{Conclusion}

This study represents an attempt to examine the arbitrage relationship between unemployment and inflation in 
Lebanon. The database used was retrieved from the World Bank for the period between 1993 till 2014. The granger causality test was adopted, which depends on the stationarity, the integration and the co-integration as precedent conditions. The applied tests reveal that there exists a solid proof concerning the long-run causality relationship between unemployment and inflation throughout the period of the study in Lebanon. However, VECM showed that this relationship is unidirectional from unemployment towards inflation. On another level, results tell that there is no Granger-Causality between these two series.

The Phillips curve tells that there exists an inverse relationship between inflation and unemployment. Taking this curve as a reference, the main objective of many researchers was to determine a model that can be used to predict inflation in the best way, given the existence of a relationship in the short run between the two series [inflation; Unemployment].

In this study, no sufficient evidence was found to show that the Phillips curve relationship holds at the level of the Lebanese economy. One possible explanation to that is the economic instability in Lebanon. Studies have found that the relationship between inflation and unemployment in developing countries is exactly the inverse of the one that exists between them in developed countries (Nugent \& Glezakos, 1982). The Phillips curve thus fails to express the relationship between inflation and unemployment in Lebanon the same way it has failed to do so in other less developed countries.

\section{Acknowledgments}

This project has been funded with support from the Lebanese University

\section{References}

Bozdogan, H. (1987). Model Selection and Akaike's Information Criterion (AIC). Psychometrika, 52, 345-370. http://dx.doi.org/10.1007/BF02294361

Chiarini, B., \& Piselli, P. (1997).Wage Setting, Wage Curve and Phillips Curve: The Itlaian Evidence.Scottish Economic Society, 44, 544-565. http://dx.doi.org/10.1111/1467-9485.00074

Duanev, B. B. (2005). Measuring Unemployment and Inflation as Wages Functions. Cybernetics and Systems Analysis, 41, 403-414. https://doi.org/10.1007/s10559-005-0074-z

Duasa, J. (2007). Malaysian Foreign Direct Investment and Growth: Does Stability Matter. J. Economic Cooperation, 83-98.

Engle, R., \& Granger, W. (1987). Co-Integration and Error Correction: Representation, Estimation, and Testing. Econometrica, 55, 251-76. https://doi.org/10.2307/1913236

Fanelli, L. (2008). Testing the New Keynesian Phillips Curve through Vector Autoregressive Models: Results from the Euro Area. Oxford Bulletin of Economics and Statistics, 70, 53-66.

Favero, C. (1988). An Econometric Analysis of the Inflation-Unemployment Trade-Off. Giorn. Econ., 47, 45-64.

Furuoka, F. (2007). Does the "Phillips Curve" Really Exist? New Empirical Evidence from Malaysia. Economics Bulletin, 5, 1-14.

Gul, E., \& Eknic, A. (2006). The causal relationship between nominal interest rates and inflation: The case of Turkey. Scientific Journal of Administrative Development, 4, 4-69.

Juselius, K. (1998). A Structured Var for Denmark under Changing Monetary Regimes. Journal of Business \& Economic Statistics, 16, 400-411. http://dx.doi.org/10.1080/07350015

Louis, R. J., \& Balli, F. (2013). Low-inflation-targeting monetary policy and differential unemployment rate: Is monetary policy to be blamed for the financial crisis? Evidence from major OECD countries. Economic Modelling, 30, 46-564.

Nugent, J. B., \& Glezakos, C. (1982). Phillips Curves in Developing Countries: The Latin American Case. Economic Development and Cultural Change. https://doi.org/10.1086/452559

Nwala, K. (2003). Is There Still an Unemployment and Inflation Trade-Off. International Advances in Economic Research, 9, 68-168. https://doi.org/10.1007/BF02295720

Phillips, W. (1958).The Relation between Unemployment and the Rate of Change of Money Wage Rates in the United Kingdom, 1861-1957. Economica, 25, 283-299.

Ribba, A. (2006). The Joint Dynamics of Inflation, Unemployment and Interest Rates in the United States since 1980. Empirical Economics, 31, 497-511. https://doi.org/10.1007/s00181-005-0031-8 
Schreiber, S., \& Wolters, J. (2007). He Long-Run Phillips Curve Revisited: Is the Nairu Framework Data-Consistent? Journal of Macroeconomics, 29, 355-367. https://doi.org/10.1016/j.jmacro.2005.08.003

Stock, J., \& Watson, M. (1993). A Simple Estimator of Cointegrating Vectors in Higher-Order Integrated. Econometrica, 61, 783-820. https://doi.org/10.2307/2951763

Tandon, B. (1978). Inflation-Unemployment Trade-Off: The Canadian Experience. Indian Journal of Industrial Relations, 13, 277-293.

Wallich, H. (1979). Balancing Inflation and Unemployment. Society, 16, 7-13. https://doi.org/10.1007/BF02712886

Yule, U. (1926). Why Do We Sometimes Get Non-Sense Correlations between Time-Series? A Study in Sampling and the Nature of Time-Series. JRSS, 89, 1-63. https://doi.org/10.2307/2341482

\section{Copyrights}

Copyright for this article is retained by the author(s), with first publication rights granted to the journal.

This is an open-access article distributed under the terms and conditions of the Creative Commons Attribution license (http://creativecommons.org/licenses/by/4.0/). 